\author{
ENGENHARIA ELÉTRICA
}

\title{
SEGURANÇA EM INSTALAÇÕES ELÉTRICAS
}

\author{
SECURITY IN ELETRICAL INSTALLATIONS
}

Yan Rodrigues - yanrodrigues17@ hotmail.com Antônio Pinto do Nascimento Neto - apnascimentoneto@ uniara.edu.br Uniara - Universidade de Araraquara -Araraquara -São Paulo -Brasil

\begin{abstract}
RESUMO
O Brasil ainda apresenta números elevados de casos de acidentes no trabalho, muitos deles gerando mortes ou incapacidade laboral permanente. Existem muitos fatores que explicam essa realidade, dentre eles destaca-se a ainda insipiente conscientização quanto à aplicação de regras de segurança antes, durante e depois das atividades de trabalho. No que diz respeito aos acidentes de trabalho em instalações elétricas esse quadro não se mostra muito diferente, portanto, este trabalho busca contribuir para a discussão sobre a aplicação das normas de segurança em instalações elétricas. Para isso foi realizada uma ampla pesquisa bibliográfica em bases de dados eletrônicas que resultou em considerável número de textos sobre o tema e sua interconexão.
\end{abstract}

Palavras-chave: Segurança no trabalho. Instalações Elétricas. Normas Regulamentadoras. NR10.

\begin{abstract}
Brazil still has high numbers of cases of accidents at work, many of them leading to deaths or permanent work disability. There are many factors that explain this reality, among them the still incipient awareness regarding the application of safety rules before, during and after work activities stands out. With regard to work accidents in electrical installations, this picture is not very different, therefore, this work seeks to contribute to the discussion on the application of safety standards in electrical installations. For this, an extensive bibliographic research was carried out in electronic databases, which resulted in a considerable number of texts on the subject and its interconnection.
\end{abstract}

Keywords: Safety at work. Electrical Installations. Regulatory Standards. NR-10. 


\section{INTRODUÇÃO}

Este trabalho tem como objetivo a análise bibliográfica de artigos, teses e dissertações que abordem os riscos de trabalhos realizados em instalações elétricas, as consequências dos acidentes e como a NR-10 determina as formas de proteção nesses ambientes.

Acidentes de trabalho são um dos principais causadores de invalidez parcial ou permanente e mortes no Brasil. Dados do INSS (2020) demonstram que mais de 20 mil brasileiros perderam a vida ao executar as tarefas do trabalho entre os anos de 2002 e 2020, dentre os países que compõem o G-20, o Brasil é o segundo maior em óbitos, com uma taxa de 6 mortes a cada 100 mil empregados, perdendo apenas para o México, que apresentou 8 óbitos a cada 100 mil.

Especificamente sobre acidentes com eletricidade, a Associação Brasileira de Conscientização para Perigos da Eletricidade (ABRACOPEL), em seu anuário 2020, ano base 2019, apresenta dados preocupantes sobre essa situação. Foram 1.662 acidentes, sendo 821 com vítimas fatais. No recorte por tipo de acidente, foram $56 \%$ por choques, 39\% por incêndios e 5\% por descarga atmosférica.

Essa realidade demonstra que é preciso estabelecer normas e diretrizes muito claras e objetivas sobre a redução dos riscos inerentes ao trabalho e, como veremos ao longo deste texto, aplicar de maneira correta e consciente as orientações presentes na NR-10 sobre trabalhos em instalações elétricas.

É muito comum, ainda, que os profissionais e empresas brasileiros destinem às regras de segurança pouco valor, principalmente quando a atividade é executada por muitos anos, causando, assim, autoconfiança exacerbada e possibilitando descuidos muitas vezes incompreensíveis.

Além disso, verifica-se constantemente que a cultura da segurança é colocada como empecilho por ser considerada uma redução de produtividade e/ou gastos/custos para as empresas.

Dado o elevado número de incipiente conscientização dos trabalhadores sobre a importância da segurança no acidentes em instalações elétricas e a ainda trabalho, esta pesquisa se dedica a analisar estudos anteriores sobre os métodos de se realizar atividades em instalações elétricas com o máximo de segurança para os trabalhadores diretamente envolvidos e os demais indivíduos que possam sofrer as consequências da manutenção nos equipamentos energizados.

${ }^{1}$ Graduando no Curso Bacharelado de Engenharia Elétrica. Yan Rodrigues

${ }^{2}$ Orientador Docente do curso Engenharia Elétrica - Antônio Pinto do Nascimento Neto. 


\section{REVISÃO BIBLIOGRÁFICA}

\subsection{Eletricidade e choque elétrico}

A eletricidade é um fenômeno natural que ocorre em consequência da movimentação de cargas elétricas na atmosfera, podendo ter como condutor diversos tipos de materiais como água, ferro, aço, cobre, etc. (BONILHA, 2017).

Do ponto de vista da física, a eletricidade é resultante do movimento nas partículas chamadas elétrons, que têm baixíssima carga fundamental, aproximadamente $1,5^{\star} 10^{-19}$. Quando esses elétrons são estimulados, eles podem criar correntes elétricas, dentre outros eventos. (BONILHA, 2017).

O fenômeno mais conhecido de eletricidade é o raio, portanto, é possível dizer que a eletricidade sempre esteve presente na história humana, encantando e promovendo fascínio e temor ao mesmo tempo. Os povos antigos sempre atribuíram a esses fenômenos alguma personificação na tentativa de explicá-los e/ou compreendê-los, com isso, foram surgindo várias divindades e histórias sobre o uso de raios como forma de punição e alerta para os incautos. (CAMISASSA, 2019; BONILHA, 2017).

Podemos dizer que os primeiros estudos sobre eletricidade foram produzidos na Grécia antiga pelo filosofo e matemático Tales de Mileto (624 a 546 a.C.) que, ao observar a capacidade do âmbar em gerar atração de pequenos materiais após ser esfregado com uma tira de couro. (DUL, WEERDMEESTER, 2019)

Desde então muitos foram os estudiosos que se debruçaram sobre esse fenômeno para extrair dele conhecimento e desenvolver formas de controlá-lo. Foi assim que em 1660 van Guericke criou uma máquina produtora de cargas elétricas através do atrito, em 1831 Faraday estabeleceu os princípios da indução eletromagnética, em 1890 Tesla projetou o sistema de corrente alternada. (BONILHA, 2017).

Como a eletricidade é um evento que não se pode perceber visualmente, uma barra de ferro carregada eletricamente não possui nenhuma característica visível ao olho humano, por exemplo, é muito comum que ocorram acidentes ao se manusear equipamentos e/ou objetos eletrificados. A essas ocorrências dá-se o nome de choque elétrico, que pode causar danos em vários níveis de intensidade ao corpo, inclusive levando o sujeito a óbito. (BONILHA, 2017).

\footnotetext{
${ }^{1}$ Graduando no Curso Bacharelado de Engenharia Elétrica. Yan Rodrigues

${ }^{2}$ Orientador Docente do curso Engenharia Elétrica - Antônio Pinto do Nascimento Neto.
} 
O choque elétrico ocorre quando há um fechamento da corrente elétrica em um circuito que passa pelo objeto eletrificado, o corpo humano e a terra, sendo que o primeiro e o último ponto possuem diferença de potencial elétrico. (LOURENÇO, LOBÃO, 2017).

É possível dividir o choque elétrico em dois tipos básicos:

- Eletrostático: ocorre quando a descarga elétrica passa de um ponto de maior potencial elétrico para outro de menor potencial. Um exemplo muito comum desse tipo de choque é o atrito entre um objeto em movimento e o ar, que cria um campo de carga elétrica positiva e, por conseguinte, aumenta a diferença entre a carga do objeto e do solo. Os choques eletrostáticos são potencialmente perigosos por causaram grandes danos a estruturas e aos produtos eletrônicos, principalmente quando ocorrem em locais com produtos químicos próximos.

- Dinâmico: surge do contato com materiais eletricamente energizados. É o tipo mais perigoso para o corpo humano porque o transforma em condutor da eletricidade entre o objeto eletrificado e o solo. A corrente elétrica que percorre o corpo pode causar grandes danos aos órgãos e tecidos, principalmente queimaduras na pele. 
Ao passar pelo corpo humano a corrente elétrica faz dele uma parte do circuito energizado e é isso que gera os danos aos órgãos, a intensidade do choque, o valor da tensão e a área de contato, presença ou não de umidade e o percurso percorrido pela corrente são os fatores que determinam as consequências que o acidente gerará. O percurso da corrente elétrica é definido pelo ponto de contato do indivíduo com o objeto eletricamente carregado, conforme demonstrado na figura abaixo. (MAHLE, 2018)

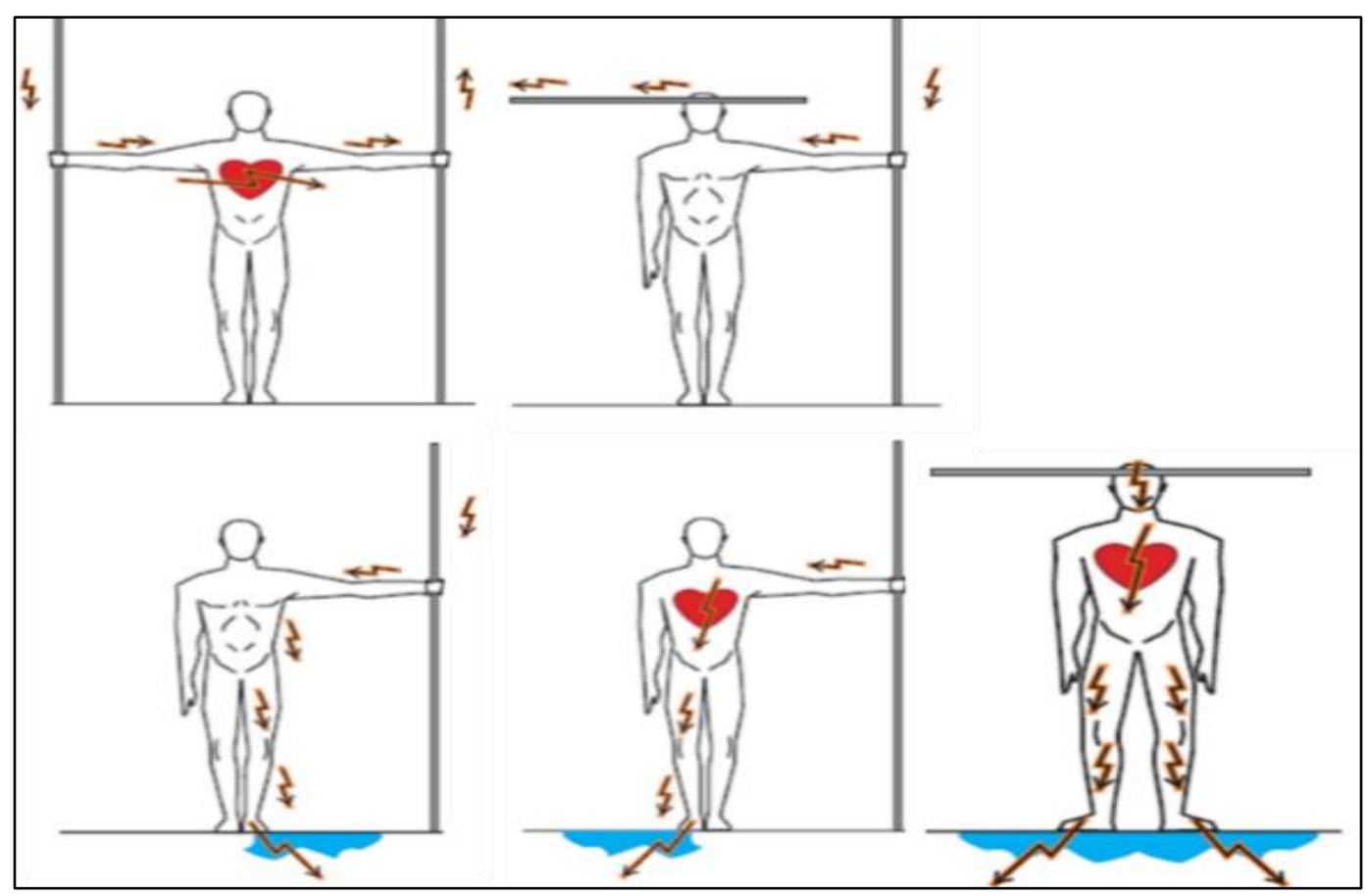

Uma vez que a intensidade do choque está atrelada às características da corrente, é importante dizer que, quando o contato se dá em uma corrente contínua os danos aos órgãos são menores quanto menor for o tempo de contato. (NUNES, 2019).

Por outro lado, se o contato for em corrente alternada $(60 \mathrm{~Hz})$, a corrente passa a ser muito mais perigosa porque a frequência da corrente está perto da fibrilação cardíaca. Portanto, o indivíduo corre mais risco de vida por que o coração passa a ser o órgão mais afetado. (VILLAIN, 2017).

$\mathrm{Na}$ maioria dos casos de acidentes evolvendo eletricidade as vítimas apresentam queimaduras porque a corrente elétrica atinge o organismo através do revestimento cutâneo. Devido à alta resistência da pele, a passagem da corrente elétrica produz alterações estruturais no organismo. As queimaduras provocadas pela

${ }^{2}$ Orientador Docente do curso Engenharia Elétrica - Antônio Pinto do Nascimento Neto. 
eletricidade diferem daquelas causadas por efeitos químicos, térmicos e biológicos. (NUNES, 2019).

\subsection{Riscos ambientais}

Todo tipo de trabalho possui algum risco inerente a ele que pode gerar consequências danosas ao corpo humano. Esses riscos são classificados em grupos: físicos, biológicos, químicos e ergonômicos, cada um deles oferece um tipo diferente de dano e necessita de diversas formas para contenção com o objetivo de reduzir os prejuízos causados à saúde do trabalhador. (VILLAIN, 2017).

No Brasil, as principais regras para contenção de riscos em ambientes de trabalho estão contidas nas 37 Normas Regulamentadoras (NR's), instituídas em 1977 como complementação ao Capítulo V da Consolidação das Leis do Trabalho (CLT), com o objetivo de garantir procedimentos de saúde e segurança no trabalho, evitando a ocorrência de acidentes ou doenças das atividades. (CAMISASSA, 2019; BONILHA, 2017).

Para este estudo a norma regulamentadora a ser mais citada será a de número 10, que apresenta orientações sobre a proteção em instalações elétricas. No entanto, outras normas serão citadas, tais como a número 9, que determina o PPRA, Plano de Prevenção de Riscos Ambientais. (ZOCCHIO, 2016).

Em linhas gerais é possível estabelecer três maneiras de se reduzir, ou até mesmo eliminar, os riscos no ambiente de trabalho: 1) proteger o indivíduo por meio do uso de EPI; 2) reduzir o efeito do agente prejudicial; 3) isolar a fonte do risco.

Nas atividades relacionadas à energia elétrica, os trabalhadores estão expostos a riscos físicos, ou seja, ao choque elétrico, que se caracteriza pela passagem de uma corrente elétrica pelo corpo humano. Isso pode gerar contração muscular, paradas cardiorrespiratórias e queimaduras na pele. (ZOCCHIO, 2016).

As queimaduras, que são os casos mais comuns de acidentes elétricos, ocorrem porque é a pele o primeiro contato que a corrente elétrica tem com o corpo, como há uma alta resistência, a passagem da eletricidade desestrutura o revestimento cutâneo. (CAMISASSA, 2019; BONILHA, 2017).

\footnotetext{
${ }^{1}$ Graduando no Curso Bacharelado de Engenharia Elétrica. Yan Rodrigues

${ }^{2}$ Orientador Docente do curso Engenharia Elétrica - Antônio Pinto do Nascimento Neto.
} 
Mesmo nos casos em que a queimadura aparentemente é superficial, é possível que existam danos aos músculos e órgãos. As queimaduras provocadas pela eletricidade diferem daquelas causadas por efeitos químicos, térmicos e biológicos.

\subsection{A NR-10}

Esta Norma Regulamentadora tem como objetivo a definição de requisitos e as condições básicas para a implantação de ações que visem o controle e a prevenção de acidentes em sistemas elétricos. A norma também visa garantir a segurança dos trabalhadores diretos e indiretos que atuam na instalação elétrica, bem como das demais pessoas que possam transitar pelo local. (ZOCCHIO, 2016, BONILHA, 2017).

A NR-10 alcança todas as fases do sistema elétrico, desde a geração até o consumo, passando pela transmissão e distribuição, além de estabelecer regras para a elaboração dos projetos de construção e montagem de sistemas elétricos.

Esses procedimentos de segurança adotados pela norma passam pela conscientização dos operadores em manterem-se seguros para a realização de suas atividades, reduzindo, dessa forma, os possíveis acidentes aos quais estão expostos.

Existem, basicamente, três medidas de controle para evitar-se os riscos de acidentes com eletricidades, são elas: medidas de proteção coletiva, medidas de proteção individual e procedimentos de trabalho.

As medidas de proteção coletiva se caracterizam pelo isolamento total ou parcial da fonte de risco elétrico, sua demarcação e sinalização e, principalmente, a desenergização de todo o sistema ou circuito. Quando o desligamento do sistema não for possível a NR-10 recomenda a execução do trabalho somente após o estabelecimento da tensão de segurança.

Já as medidas de proteção individual atuam como um reforço para a proteção gerada pelo controle coletivo, elas consistem na utilização de Equipamentos de Proteção Individual (EPl's) que sejam adequados para a contensão de danos elétricos ao corpo do trabalhador.

A norma que trata dos equipamentos de proteção é a NR-06, nela está estabelecido que o EPI é todo e qualquer dispositivo ou material de uso individual capaz de conter os possíveis danos que o trabalhador está exposto. Esses

${ }^{2}$ Orientador Docente do curso Engenharia Elétrica - Antônio Pinto do Nascimento Neto. 
equipamentos devem ser constituídos por materiais que cumpram a função de isolar o trabalhador, apresentando boa condutibilidade e baixa inflamabilidade.

A responsabilidade pela adoção dessas medidas é, em sua totalidade, da empresa contratante, cabendo a ela informar os trabalhadores sobre os riscos aos quais estão expostos, orientando-os quanto aos procedimentos-padrão para utilização dos equipamentos de proteção e o estabelecimento das medidas de isolamento da fonte do risco. (ZOCCHIO, 2016).

Segundo a NR-10, o trabalho em instalações elétricas deve ser devidamente adequado para o local em que a atividade é realizada e aos equipamentos que serão utilizados. Todas as medidas de proteção devem ser tomadas levando-se em consideração as condições externas, como presença de água, corpos sólidos, pessoas que utilizam a instalação e materiais utilizados. (LOURENÇO, LOBÃO, 2017).

Da mesma forma que as normas estrangeiras, a NR-10 busca pelo estabelecimento de princípios gerais de segurança ou, em alguns pontos, pela complementação de algumas normas contidas na Associação Brasileira de Normas Técnicas (ABNT). São as normas técnicas que se encarregam de trazer recomendações mais específicas sobre atuação em instalações elétricas, das quais destacam-se: (LOURENÇO, LOBÃO, 2017).

I. NBR 5410: instalações elétricas de baixa tensão.

II. NBR 5418: instalações elétricas em atmosferas explosivas.

III. NBR 5419: proteção em estruturas contra descargas atmosféricas.

IV. NBR 13534: instalações elétricas em estabelecimentos assistenciais de saúde, requisitos para segurança.

V. NBR 13570: instalações elétricas em locais de afluência de público.

VI. NBR 14039: instalações elétricas de média tensão de 1,0 kV a 36,2kV.

VII. $\quad$ NBR 14639: posto de serviço, instalações elétricas.

A NR-10 determina também que os trabalhos em instalações elétricas devem seguir todas as normas oficiais definidas, em caso da ausência de alguém orientação oficial, deve-se seguir a normatização internacional. (LOURENÇO, LOBÃO, 2017). 
O órgão que determina a definição de normas internacionais é a Organização Mundial do Comércio (OMC) ao estabelecer o Acordo de Barreiras Técnicas ao Comércio, do qual o Brasil é signatário.

\subsection{Instalações elétricas}

Uma instalação elétrica pode ser definida, basicamente, como sendo um conjunto de condutores e equipamentos elétricos que visam o transporte de energia com segurança e qualidade para o usuário (JANES, 2019).

A concepção de um projeto de instalação elétrica deve sempre considerar a presença e o impacto de diversas variáveis, bem como sua influência no desempenho do sistema. Para isso, o profissional projetista deve se guiar pelas normas estabelecidas. (LOURENÇO, LOBÃO, 2017).

Os trabalhos em instalações elétricas no Brasil podem gerar grandes acidentes, como incêndios, somente em 2019 foram mais de 650 incêndios por sobrecarga (ABRACOPEL, 2020). Isso ocorre porque boa parte das instalações, tanto residenciais quanto industriais, encontra-se em condições precárias ou em baixo grau de segurança, sem a devida manutenção ou reposição de equipamentos. (LOURENÇO, LOBÃO, 2017).

Na figura 1 é apresentada a relação de principais locais de acidentes que foram atendidos pelo Corpo de Bombeiros somente no estado de São Paulo. Esses dados demonstram a baixa qualidade nas instalações elétricas e que as principais vítimas são pessoas em suas residências.

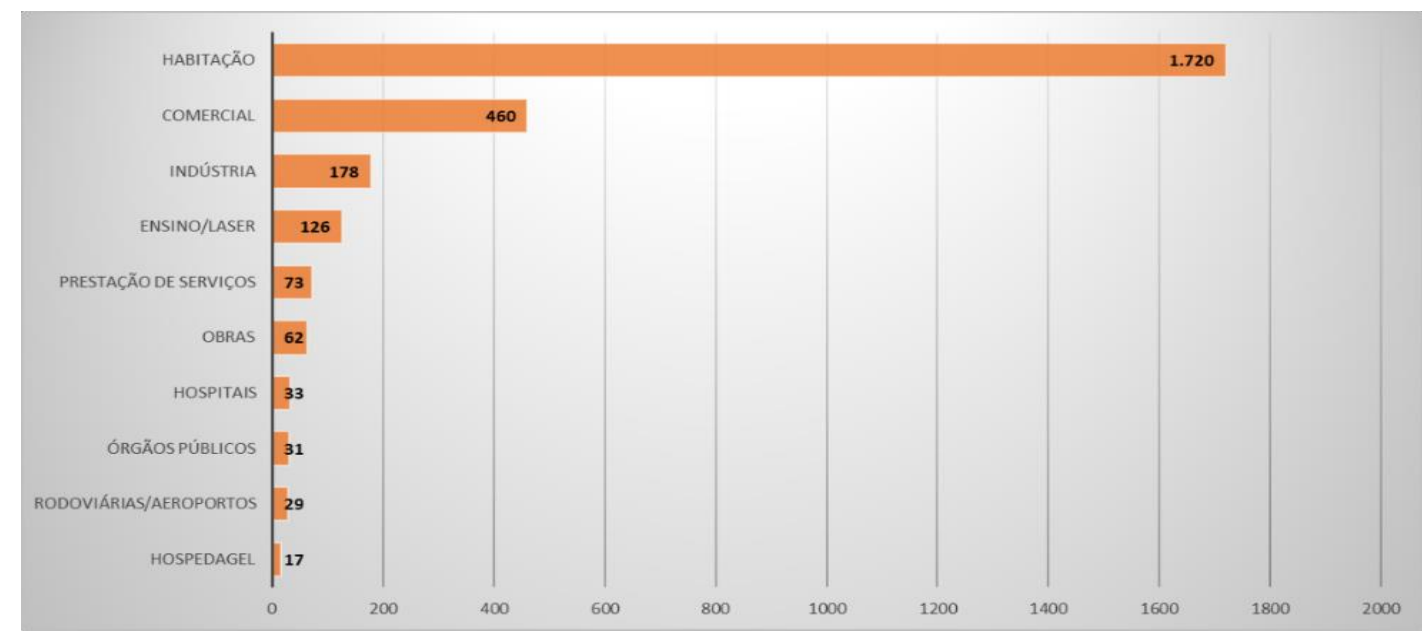

\section{Fiaura 1 Acidentes em instalacões elétricas}

Fonte: Adabtado de Janes (2019).

${ }^{1}$ Graduando no Curso Bacharelado de Engenharia Elétrica. Yan Rodrigues

${ }^{2}$ Orientador Docente do curso Engenharia Elétrica - Antônio Pinto do Nascimento Neto. 
No trabalho de Santos Junior (2018), ao analisar as instalações elétricas em indústrias de pequeno e médio porte, verificou-se que a maior parte, cerca de $45 \%$, possuem baixa segurança elétrica, com redes energizadas expostas, cabos sobrecarregados, isolamento e dimensionamento inadequados.

$O$ autor também constatou que o risco de incêndio nessas empresas era alto, tendo em vista os diversos pontos de curto-circuito, exposição de fios e falhas nas conexões. Em aproximadamente $60 \%$ das empresas pesquisas foram encontrados disjuntores instalados próximos ou diretamente em bases de madeira sem a devida proteção.

\subsection{Proteção do trabalhado em instalações elétricas}

Segundo dados da ABRACOPEL (2020), somente em 2019 foram 1.662 acidentes envolvendo trabalhos em eletricidade, que causaram mais de 800 mortes, um aumento de 16,70\% em relação ao ano de 2019.

No entanto, a mesma ABRACOPEL (2020) estima que esses dados podem estar subnotificados e que o número real estaria em torno de 45 mil casos e mais de 20 mil mortes.

Sendo assim, é imprescindível que o trabalhador tenha o máximo de proteção possível ao executar suas atividades nas instalações elétricas. $O$ início dos trabalhos deve considerar o exposto no item 10.5 da NR 10, que descreve a sequência exata de procedimentos para a desenergização do sistema, a saber (JANES, 2019; LOURENÇO, LOBÃO, 2017):

\section{Seccionamento}

Esse procedimento é necessário para a redução total da continuidade da corrente elétrica, utiliza-se para isso uma chave-faca seccionadora, vara de manobra ou acionamento do disjuntor.

\section{Impedimento de reenergização}

Tem como objetivo o controle do trabalhador sobre a região seccionada, de forma a não permitir a reenergização. São utilizados travamentos mecânicos com fechaduras e/ou cadeados. Importante destacar que somente pessoas autorizadas e

\footnotetext{
${ }^{1}$ Graduando no Curso Bacharelado de Engenharia Elétrica. Yan Rodrigues

${ }^{2}$ Orientador Docente do curso Engenharia Elétrica - Antônio Pinto do Nascimento Neto.
} 
capacitadas devem promover o travamento do sistema no equipamento de seccionamento, impedindo, assim, a reenergização.

É recomendado que a desenergização ocorra com planejamento e organização, informando aos usuários do sistema que haverá queda de energia, o período da execução dos trabalhos e a preparação para religação.

No item 10.5.2 da NR 10 é descrita a forma de se fazer a reenergização do sistema, a retirada dos equipamentos e ferramentas de trabalho e demais coisas utilizadas.

\section{Constatação da ausência de tensão}

Consiste na verificação do circuito elétrico quanto a ausência de tensão nos condutores, de forma a permitir uma segura execução dos trabalhos. Para isso, é fundamental a utilização de detectores aplicados antes do início do trabalho e em todos os pontos ativos da instalação na área.

Essa verificação deve ser feita em todos os equipamentos da instalação elétrica na área em que ocorrerá o trabalho e anteriormente à instalação do aterramento. $A$ razão desse procedimento é a necessidade de se evitar que ocorra alguma ligação da instalação, de forma acidental, no tempo entre a confirmação da ausência de tensão e a instalação do cabo-terra.

Os instrumentos de detecção de tensão podem apresentar a ausência ainda que exista, de fato, uma pequena tensão induzida, o importante nesses casos é que o limite mínimo do detector não seja ultrapassado. Após a realização correta do aterramento, essa pequena tensão seja neutralizada. Isso demonstra a importância de se ter equipamentos corretamente calibrados e atualizados para a execução dos trabalhos.

\section{Instalação de aterramento temporário}

A aplicação do aterramento é fundamental para garantir a manutenção da segurança na zona de trabalho ao longo de todo o período de execução das atividades. $\mathrm{O}$ condutor do circuito temporário deve ser conectado ao condutor neutro e também ao condutor de proteção que esteja mais próximo da região de trabalho.

\footnotetext{
${ }^{1}$ Graduando no Curso Bacharelado de Engenharia Elétrica. Yan Rodrigues

${ }^{2}$ Orientador Docente do curso Engenharia Elétrica - Antônio Pinto do Nascimento Neto.
} 
É preciso que se instale ligações-terra nos dois lados da zona de trabalho para garantir uma proteção global, além de se demarcar corretamente o cabo de aterramento, possibilitando sua correta visualização.

Existem algumas características da instalação que elétrica que servem como base para a determinação do equipamento de aterramento a ser utilizado, são elas:

- Nível de tensão;

- Nível máximo da corrente suportado pelo circuito;

- Nível máximo da bitola dos condutores;

- Nível máximo do comprimento do aterramento;

- Nível máximo de distância entre as fases (central e neutro).

\section{Proteção dos equipamentos energizados}

No Anexo II da NR-10 são estabelecidos os níveis de isolamento que se deve estabelecer na área de trabalho. Esse isolamento é feito por meio do uso de mantas, capuzes, mantas e demais materiais isolantes.

Na figura 2 está a representação da delimitação das áreas de trabalho, o raio é definido pelo nível de tensão nominal presente na instalação, que pode variar de $0,20 \mathrm{~m}$ para $1 \mathrm{kV}$ até $7,20 \mathrm{~m}$ para tensão acima de $700 \mathrm{kV}$.

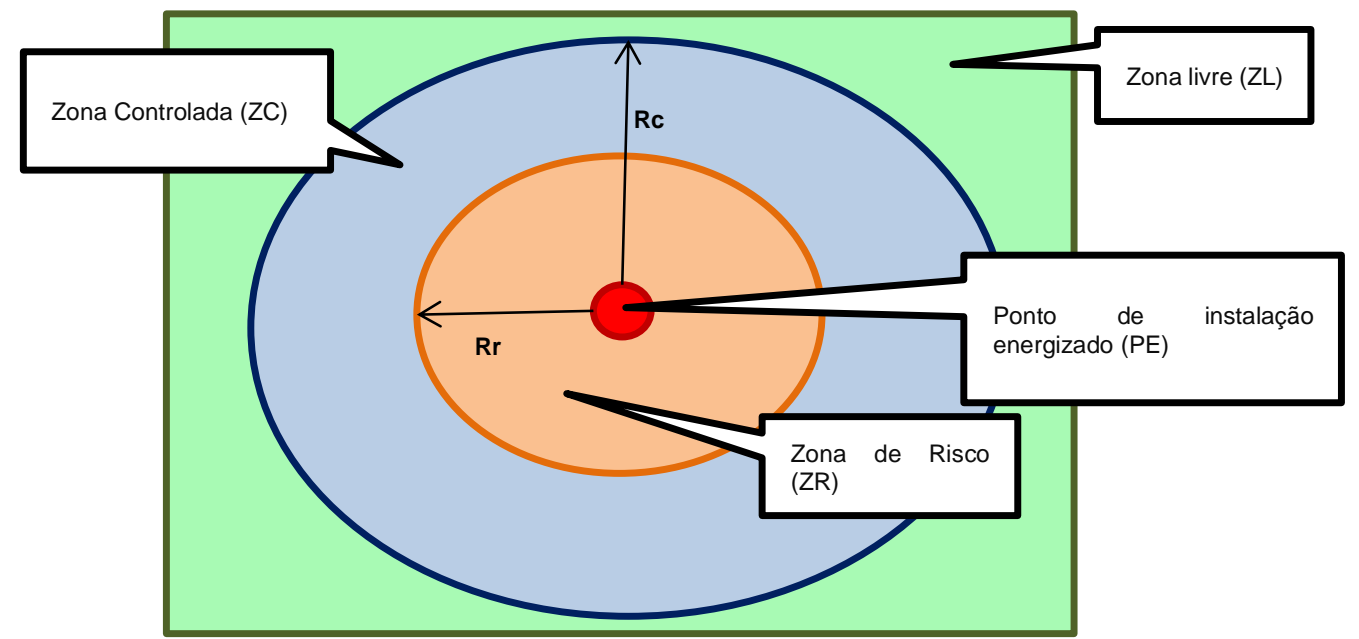

Figura 2 Definição da área de risco e controle Fonte: Adaptado de NR-10.

\section{Sinalizar o local de trabalho}

A sinalização é uma das tarefas mais importantes ao realizar trabalhos em instalações elétricas porque ela apresenta aos demais trabalhadores e, em alguns 
casos, aos passantes, os motivos para a desenergização, bem como evitar que outras pessoas sofram algum dano por entrar em contato com superfícies energizadas.

No item 10 da NR-10 é estabelecido que a sinalização deve seguir os procedimentos apresentados na NR-26, de forma que atenda às seguintes situações:

- Identificar os circuitos elétricos;

- Travar e bloquear os dispositivos e sistema de manobra;

- Impedir acesso à área de trabalho;

- Delimitar a área de trabalho;

- Identificar corretamente o circuito ou equipamento que recebe a manutenção;

$\mathrm{Na}$ figura 3 estão alguns exemplos de etiquetas que podem servir como sinalização de segurança. Ao finalizar as atividades o trabalhador fará a retirada dos equipamentos e das demais pessoas envolvidas da Zona Controlada (ZC).

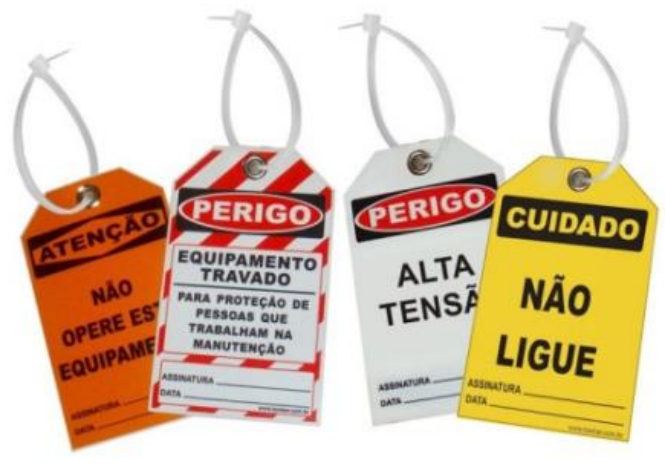

O procedinFigura 3 Modelos de etiquetas

emplada na Medida de Proteção Coletiva citada anteriormente e, sendo assim, necessita que sejam adicionadas outras medidas para que a proteção se torne o mais eficaz possível.

\section{CONCLUSÃO}

O presente trabalho buscou apresentar os principais conceitos e práticas a serem adotados a fim de garantir maior efetividade na proteção de trabalhadores que executam atividades de manutenção e/ou correção em instalações elétricas.

Para isso, foi preciso realizar uma pesquisa bibliográfica que contou com análises de diversos textos sobre o tema e aglutinou os principais resultados ao longo destas páginas. 
Verificou-se que a Norma Regulamentadora ํo 10 é bastante abrangente e cuidadosa ao descrever cada atividade e/ou exigência a serem executadas com o rigor necessário que a segurança e saúde do profissional sejam alcançadas.

Ficou demonstrado que todas as medidas para reduzir os riscos no ambiente de trabalho em instalações elétricas devem ser tomadas, porém, é fundamental que as empresas desenvolvam campanhas para a conscientização dos trabalhadores quanto a importância da segurança, de forma a reduzir os elevados índices de acidentes.

\section{BIBLIOGRAFIA}

ABRACOPEL, Acidentes com Eletricidade: ASSOCIAÇÃO BRASILEIRA DE CONSCIENTIZAÇÃO PARA OS PERIGOS DA ELETRICIDADE - ABRACOPEL. Anuário estatístico de acidentes de origem elétrica 2020, ano base 2019. Salto: >Acesso em 05 de março de 2021.

BARROS, B. F. de. NR 10, guia prático de análise e aplicação comentado. $8^{\mathbf{a}}$ ed. Campinas: Atlas, 2020. >Acesso em 05 de março de 2021.

BONILHA, J. E. A Segurança do Trabalhador: uma preocupação constante. Revista Eletrônica FTEC, v. 1, 2017. Disponível em

http://junior.ftec.com.br/revista/autor/pdf/josebonilla.pdf. >Acesso em 05 de março de 2021.

BRASIL, Ministério do Trabalho e Emprego - MTE. Norma Regulamentadora ํㅜ 10 NR 10: Segurança em instalações e serviços em eletricidade. Brasília: MTE, 2004. Disponível em http://portal.mte.gov.br/data/files/8A7C812D308E216601310641F67629F4/nr 10.pdf . > Acesso em 30 de março de 2021.

Disponível em , Portaria no 25 de 29 de dezembro de 1994. Brasília: MTE, 1994.

http://portal.mte.gov.br/data/files/FF8080812BE914E6012BEA44A24704C6/p 19941 229 25.pdf. >Acesso em 30 de março de 2021.

, Norma Regulamentadora no 5 - NR 5: Comissão Interna de

Prevenção de Acidentes. Brasília, MTE, 1978. Disponível em

${ }^{2}$ Orientador Docente do curso Engenharia Elétrica - Antônio Pinto do Nascimento Neto. 
http://portal.mte.gov.br/data/files/8A7C812D311909DC0131678641482340/nr 05.pdf . > Acesso em 30 de março de 2021.

, Norma Regulamentadora no 9 - NR 9: Programa de Prevenção de Riscos Ambientais. Brasília, MTE, 1978. Disponível em http://portal.mte.gov.br/data/files/8A7C812D311909DC0131678641482340/nr 05.pdf . >Acesso em 30 de março de 2021.

CAMISASSA, M. Q. Segurança e saúde no trabalho: NR'S 1 A 37. $6^{a}$ ed. São Paulo: Saraiva, 2019. > Acesso em 30 de março de 2021.

CAMPOS, A. CIPA - Comissão Interna de Prevenção de Acidentes: uma nova abordagem. 20를. ed. São Paulo: SENAC, 2020. > Acesso em 30 de março de 2021.

CAMPOS, A. et. al. Prevenção e controle de risco em máquinas e equipamentos e instalações. 6⿳亠丷厂 ed. São Paulo: SENAC, 2019.

> Acesso em 30 de março de 2021.

CAMPOS, A.A.M. Modelo estratégico de gestão e segurança e saúde no trabalho. Universidade Federal Fluminense. 2018. > Acesso em 30 de março de 2021.

CARNEIRO, W.R., BARRETO, G. Contribuições para o ensino da segurança na utilização de energia elétrica. SENAI-SP, 2020. > Acesso em 30 de março de 2021.

COPEL - Companhia Paranaense de Energia. Guia de segurança nas instalações elétricas. Curitiba: COPEL, 2017. Disponível em

http://www.copel.com/hpcopel/root/sitearquivos2.nsf/arquivos/dicas de seguranca n as instalacoes eletricas/\$FILE/pdf seguranca.pdf. >Acesso em 10 de março de 2021.

CUNHA, J. G. Norma Regulamentadora ํo 10 comentada. São Paulo: MiOmega, 2018. >Acesso em 30 de março de 2021.

CASTRO, S. de. Mapa de riscos: explanação completa. 2019. Disponível em http://santosde.blogspot.com.br/2019/10/mapa-de-riscos 16.html. > Acesso em 30 de março de 2021.

DUL, J.; WEERDMEESTER, B. Ergonomia prática. $6^{a}$ ed. Rio de Janeiro: Blucher, 2019. > Acesso em 30 de março de 2021.

${ }^{1}$ Graduando no Curso Bacharelado de Engenharia Elétrica. Yan Rodrigues

${ }^{2}$ Orientador Docente do curso Engenharia Elétrica - Antônio Pinto do Nascimento Neto. 
FERNANDES, A. C. A Nova Norma Regulamentadora no 10. 2017. Revista Brasil Engenharia. Disponível em http://www.brasilengenharia.com/portal/images/stories/revistas/edica0582/110Eletric a582.pdf. >Acesso em 05 de março de 2021.

JANES, R. Estudo sobre sistemas de segurança em instalações elétricas. Universidade de São Paulo. 2019. > Acesso em 30 de março de 2021.

LOURENÇO, H; LOBÃO, E. Análise de segurança do trabalho em serviços com a eletricidade sob a ótica da nova NR 10. 2017. Disponível em. http://www.dalmoro.com.br/images/publications/original/08042017161015.pdf. $>$ Acesso em 03 set. 2020.

Segurança no trabalho: análise das alterações propostas na revisão da NR 10. Seminário Internacional de Arquitetura e Urbanismo. 2018. Disponível em http://www.dalmoro.com.br/images/publications/original/08042017161136.pdf. > Acesso em 05 set. 2020.

MACHADO, F.M. Análise das perdas em instalações elétricas residenciais considerando método de instalação. VI Simpósio de Integração Científica e Tecnologica. 2017. > Acesso em 05 set. 2020.

MAHLE. Trabalho com eletricidade: procedimentos de segurança e saúde ocupacional. São Paulo: MAHLE, 2018. Disponível em http://www.mahle.com.br/C1256F7900537A47/vwContentByKey/W289ZQHU121STU LEN/\$FILE/Trabalho\%20com\%20Eletricidade.pdf. > Acesso em 10 de março de 2021.

NUNES, F. O. Segurança e saúde no trabalho esquematizada: NR-10. São Paulo: Campos Elsevier, 2019. > Acesso em 05 set. 2020.

SENAI, Serviço Nacional de Aprendizagem Industrial. NR 10: segurança em instalações e serviços em eletricidade: Reciclagem. $2^{\mathrm{a}}$ ed. São Paulo: Editora SENAI, 2018. > Acesso em 05 set. 2020.

${ }^{2}$ Orientador Docente do curso Engenharia Elétrica - Antônio Pinto do Nascimento Neto. 
PEREIRA, J. G; SOUSA, J. J. B. Manual de auxílio na interpretação e aplicação da NR-10. $2^{a}$ ed. Brasília. Ministério do Trabalho e Emprego, 2020. > Acesso em 05 set. 2020.

SILVA, S.S., MICHALOSKI, A. R. A norma regulamentadora № 10 e sua aplicação em instalações elétricas. Revista Técno-Científica do CREA-PR, abril de 2017. > Acesso em 05 set. 2020.

VILLAIN, F. S. Segurança em eletricidade: proposta de implantação da nova NR-10. [tese] Universidade Extremo-sul Catarinense. Criciúma, 2017. > Acesso em 05 set. 2020.

ZOCCHIO, A. Prática da Prevenção de acidentes: ABC da segurança do trabalho. $7^{\text {ạ }}$ ed. São Paulo: Atlas, 2016. > Acesso em 05 set. 2020. 